\title{
Projetos Digitais de Inglês na Educação Básica: reflexões, possibilidades e ações em tempos de pandemia
}

\author{
English Language Digital Projects in Middle and High School Settings: reflections, possibilities and actions in \\ pandemic times \\ Gustavo Estef Lino da Silveira \\ Universidade do Estado do Rio de Janeiro - UERJ -Rio de Janeiro - Brasil
}

\section{Andrea da Silva Marques Ribeiro}

Universidade do Estado do Rio de Janeiro - UERJ -Rio de Janeiro - Brasil

\section{Arthur Bruno Rodrigues Pedrosa}

Universidade do Estado do Rio de Janeiro - UERJ -Rio de Janeiro - Brasil

Mônica de Medeiros Villela

Universidade do Estado do Rio de Janeiro - UERJ -Rio de Janeiro - Brasil

\section{Sônia Melo de Jesus Ruiz}

Universidade do Estado do Rio de Janeiro - UERJ -Rio de Janeiro - Brasil

\begin{abstract}
Resumo: Este artigo tem como objetivo descrever os projetos digitais desenvolvidos em ambiente virtual pela equipe de língua inglesa do Instituto de Aplicação Fernando Rodrigues da Silveira, CAp-UERJ, como meio de atendimento aos estudantes da educação básica do instituto durante o período de distanciamento social imposto pela pandemia do novo coronavírus. Os projetos digitais tiveram como fundamentação o Design Instrucional Contextualizado - DIC (FILLATRO, 2004; REIGELUTH, 1999), para a organização do trabalho no ambiente virtual de aprendizagem e o Project Based Learning - PBL (BELL, 2010; BLUMENFELD, 1991; BLUMENFELD e KRAJCIK, 2006; BENDER, 2014), para a elaboração das unidades do projeto. O PBL preconiza a investigação e o incentivo à autonomia por meio de tarefas colaborativas sobre temas relevantes que culminam em um produto ou apresentação públicos e autênticos. O trabalho on-line possibilitou a reestruturação dos projetos em termos de divisão do trabalho, reorganização de cronograma e releitura dos papéis de professores e alunos. As atividades que compuseram as unidades dos projetos se configuraram em oportunidades de desenvolvimento de letramento digital, autonomia, aprofundamento do conhecimento multidisciplinar e de habilidades que os estudantes precisam usar e aplicar e serem também capazes de transferir para outros contextos no futuro.
\end{abstract}

Palavras-chave: Ensino de Língua Inglesa na Educação Básica. Pandemia. Project Based Learning (PBL). Design Instrucional Contextualizado (DIC).

Abstract: This article aims at describing the digital projects developed in a virtual environment by the English teachers from Fernando Rodrigues da Silveira Application Institute, CAp-UERJ, as a means of assisting its middle and high school students during the period of social distancing imposed by the new coronavirus pandemic. The digital projects were based on the Contextualized Instructional Design - CID (DIC, in Portuguese); (FILLATRO, 2004; REIGELUTH, 1999), for the organization of work in the virtual learning environment, and on the Project Based Learning - PBL methodology (BELL, 2010; BLUMENFELD, 1991; BLUMENFELD e KRAJCIK, 2006; BENDER, 2014), for the preparation of the project units. PBL advocates research and encourages students' autonomy through collaborative tasks on relevant topics that culminate in a public and an authentic product or presentation. The online work made it possible to restructure the projects in terms of the division of labor among the group of teachers, reorganization of the schedule and also the reformulation of the roles of teachers and studentsin the project. Thus, the activities that comprised the units of the projects were then, distinguished opportunities for the development of digital literacy, autonomy, deepening the multidisciplinary knowledge and skills that students needed to use and apply and also to be able to transfer to other contexts in the future. 
Keywords: English language learning in Middle and High School. Pandemic. Project Based Learning (PBL). Contextualized Instructional Design (CID).

\section{Introdução}

Em meados de março de 2020, devido à pandemia de COVID-19, o Instituto de Aplicação Fernando Rodrigues da Silveira, doravante CApUERJ, compreendeu a necessidade de pausar as suas atividades presenciais e oferecer atendimento acadêmico remoto aos seus estudantes e, assim, como outras instituições de ensino, deu início à reconfiguração de seu planejamento pedagógico. Inserida nesse contexto, a equipe de professores de língua inglesa do instituto viu-se desafiada a oferecer aos estudantes dos anos finais do ensino fundamental (EFII) e do ensino médio (EM) possibilidades de contato com o idioma de forma autêntica e relevante utilizando 0 ambiente virtual de aprendizagem, AVACAp. Esse ambiente - em funcionamento desde 2013, que utiliza a plataforma Moodle para o contato e a oferta de atividades aos estudantes como apoio ao ensino presencial - tornou-se, em meio à pandemia, a plataforma institucional do CAp-UERJ, para o que foi chamado de "Contato Capiano": o acolhimento e atendimento remoto aos estudantes por meio de atividades on-line não compulsórias.

A equipe de língua inglesa aderiu à proposta de atendimento remoto aos estudantes elaborando projetos digitais de inglês especificamente para os estudantes da educação básica, tendo a concepção de Design Instrucional Contextualizado (DIC) como base, que pautou o trabalho da equipe no ambiente virtual e o Project Based Learning (PBL) como arcabouço teórico-metodológico, para a elaboração das atividades.

O PBL foi escolhido como metodologia norteadora das ações pedagógicas nesse projeto primeiramente por encorajar a autonomia dos estudantes e não demandar, necessariamente, ações interativas síncronas entre professores e alunos - uma vez que seu campo de ação envolve o engajamento próprio dos alunos em pesquisa e investigação para a construção de conhecimento e aquisição de habilidades através do cumprimento de tarefas com base em atividades autênticas. Sendo assim, o PBL mostrou ser a opção metodológica mais acertada, não só por atender aos anseios de contato da equipe de professores de inglês com o corpo discente, mas também por ser capaz de promover oportunidades para os alunos de construção de conhecimento e de desenvolvimento da língua inglesa. As próximas seções apresentam a estrutura dos projetos digitais e descrevem o processo de design e organização dos projetos à luz do Design Instrucional Contextualizado (DIC) e da metodologia PBL.

\section{Projetos digitais de inglês em educação}

\section{básica}

A organização dos projetos foi planejada de modo a atender aos diferentes níveis de escolaridade agrupados em salas virtuais, o que difere do modelo de turmas, habitualmente usado no modo presencial. Decidimos atender ao 6ํㅡㅁ ano do EF em uma única sala virtual, porque entendemos que esses estudantes estão em processo de familiarização com o aprendizado sistematizado do inglês no ambiente escolar e, portanto, necessitam de atividades menos complexas, visto que é nesse ano de escolaridade que se inicia o ensino obrigatório desse idioma como língua estrangeira na educação básica. Os outros anos de escolaridade foram agrupados por duplas nas demais salas virtuais. Dessa forma, criamos quatro salas com a seguinte composição: " 60 ano do EF", "70 e $8^{\circ}$ anos do EF", "9 ${ }^{\circ}$ ano do EF e $1^{\circ}$ ano do EM" e " $2^{\circ}$ e $3^{\circ}$ anos do EM". Tal organização levou em consideração aspectos como as faixas etárias dos alunos, os temas a elas pertinentes e a nossa capacidade de força de trabalho para elaborar e mediar as atividades nesse primeiro momento de atendimento remoto, ainda novo para todos.

Cada sala virtual, composta como explicado acima, participou de um projeto específico. A temática de cada projeto foi desenvolvida a partir de uma pergunta motriz: "De que forma o inglês está presente no meu cotidiano?" ( $6^{\circ}$ ano); "Qual tem sido a minha rotina na quarentena?" ( $7^{\circ}$ e $8^{\circ}$ anos); "Como posso 
reduzir minha pegada ecológica no meio-ambiente?" ( $9^{\circ}$ ano do EF e $1^{\circ}$ ano do EM) e "Como será a minha vida durante e após a pandemia?" $\left(2^{\circ}\right.$ e $3^{\circ}$ anos do EM). Essas perguntas instigaram os alunos a refletir e investigar outros questionamentos - desdobramentos da pergunta inicial - que foram trabalhados de acordo com um cronograma preestabelecido.

Ao nortear a temática de cada etapa de trabalho, o objetivo era que o aluno construísse um produto final que representasse uma possível resposta à pergunta motriz e evidenciasse o seu aprendizado ao longo da implementação do projeto.

Todos os projetos foram estruturados seguindo as mesmas etapas. No início, as atividades eram disponibilizadas semanalmente. Em cada semana era apresentada uma nova unidade do projeto, o que, posteriormente, passou a ser feito quinzenalmente. As primeiras unidades disponibilizadas foram "Ambientação" e "Project Overview", nessa ordem. A Ambientação continha um painel intitulado "The English Team", com fotos dos professores, acompanhadas de um breve texto com a apresentação dos mesmos; um fórum intitulado "Dúvidas e Perguntas"; onde os alunos puderam postar questões relativas ao funcionamento e utilização das atividades no ambiente virtual; um fórum chamado "Recess Time", para os alunos se apresentarem e conhecerem uns aos outros, dizendo o que gostavam de fazer e como estavam lidando com a quarentena e o distanciamento social. Incluímos também um questionário de sondagem, elaborado utilizando-se a ferramenta Google Forms, cujo objetivo era coletar informações sobre a experiência e o interesse do aluno em relação à língua inglesa e investigar questões relacionadas ao acesso à internet e ao conhecimento das ferramentas digitais a serem utilizadas no projeto. Ao traçar o perfil desse aluno, pretendíamos identificar possíveis dificuldades que pudessem interferir na participação nos projetos e agir de maneira proativa para o bom andamento dos trabalhos. A unidade Project Overview apresentou a visão geral de cada projeto, resumindo a proposta de trabalho, além de descrever os objetivos gerais, a temática e o cronograma das atividades.
Nas unidades seguintes, a proposta foi a de construção de conhecimento tendo como base a pergunta motriz e seus desdobramentos. Nessa etapa, promoveu-se a investigação constante por meio das seguintes atividades:

A. Vocabulary Log: permitiram a inserção de palavras ou expressões novas identificadas nos diferentes textos trabalhados durante as atividades por parte dos professores e estudantes, formando um glossário colaborativo.

B. Pre-listening/ viewing/ reading: ativaram o conhecimento prévio dos alunos quanto ao assunto a ser tratado nos textos.

C. While-listening/ viewing/ reading: visaram à interpretação e a compreensão das características textuais e discursivas de textos multimodais, tais como imagens, vídeos, textos escritos, dentre outros, para fomentar o aprendizado da língua por meio de exposição a um input compreensível e autêntico, de modo a fomentar a aquisição da língua (KRASHEN, 2002).

D. Language Corner: informaram e explicaram aspectos lexicogramaticais, chamando a atenção dos estudantes para determinados itens ou expressões linguísticas, sem a intenção de estruturálas ou consolidá-las através da prática de exercícios.

E. Post-listening/ viewing/ reading: oportunizaram o posicionamento crítico e informado sobre os temas trabalhados nas atividades.

F. Challenge!: incentivaram a elaboração e a apresentação de um produto final, público e autêntico, por parte dos alunos, com base nas experiências desenvolvidas ao longo das atividades anteriores, tal como a produção de textos e a postagem de fotos e imagens em geral. Tais produtos eram compartilhados com os outros participantes em espaços a isso destinados. Todos esses desafios demandaram o uso de ferramentas e aplicativos digitais autênticos e diferentes a cada semana ou quinzena. Para contribuir com os processos de letramento digital e orientar no uso das ferramentas tecnológicas, foram também disponibilizados tutoriais e exemplos que ajudaram os estudantes a realizar as atividades Challenge!. Cada 
um desses desafios representou andaimes (milestones) importantes na elaboração da tarefa de culminância, ao fim do projeto.

G. Before you leave: promoveram a reflexão dos alunos sobre a própria aprendizagem ao longo das atividades da quinzena e os incentivaram a dar sugestões e a atuar de forma crítica, escrevendo comentários sobre o projeto, em um fórum específico para esse fim.

$\mathrm{Na}$ penúltima quinzena de cada projeto, os estudantes executaram uma tarefa de culminância, que os levou a concretizar um "produto público", tal como um pôster on-line, um pledge on-line, um mural on-line etc., em resposta às perguntas motrizes introdutórias. Essa tarefa representou uma compilação dos resultados e produções das atividades Challenge! e tal como elas, também demandaram a utilização de ferramentas digitais. Para auxiliar os estudantes, a execução de algumas tarefas foi exemplificada e explicada em tutoriais por meio de vídeo.

Além disso, o projeto também incluiu as unidades Time to Play e The Sound of Music, que serão detalhadas na seção 3.

Para concluir os projetos, os estudantes fizeram a autoavaliação de sua participação a fim de refletir sobre a sua experiência e papel no desenvolvimento da própria aprendizagem da língua inglesa.

O desenho inicial dos projetos digitais de inglês na educação básica evidencia dois desafios: o primeiro é o processo de design do projeto e a organização do trabalho da equipe no ambiente virtual de aprendizagem (AVACAp). O segundo configura-se na elaboração das atividades das unidades para o desenvolvimento da língua inglesa. Ambos os processos são complexos, tendo em vista as suas especificidades. Sendo assim, nesse estudo, o processo de design e organização dos projetos é descrito e analisado à luz do Design Instrucional Contextualizado (DIC) e a elaboração das atividades de inglês são pautadas pela metodologia do Project Based Learning (PBL).
3 Design Instrucional Contextualizado: os projetos digitais de inglês na educação básica como processo e produto

Em uma concepção de design instrucional tradicional, as fases do processo de um projeto educacional são bastante demarcadas e geralmente assumem um tom prescritivo (REIGELUTH, 1999), já que se baseiam na previsão de situações e nos resultados esperados. Um modelo tradicional de design instrucional para contextos educacionais é normalmente organizado em cinco fases, que ocorrem sequencialmente: análise, design, desenvolvimento, implementação e avaliação. A primeira fase, ou "análise", trata do levantamento de necessidades, da caracterização do público-alvo, da análise da infraestrutura da instituição e dos recursos tecnológicos disponíveis. A segunda fase, o "design", é quando se estabelece a equipe de trabalho, as estratégias pedagógicas e as ferramentas tecnológicas do projeto. Nessa fase, também se elaboram os cronogramas de trabalho. A terceira fase, ou "desenvolvimento", refere-se à produção dos materiais, elaboração das atividades e configuração do suporte. Na quarta fase, a "implementação", o foco recai sobre a situação didática e a organização da aprendizagem. Essa fase é concretizada na forma de disponibilização dos conteúdos e na maneira como os estudantes e professores agirão sobre eles. Por fim, na quinta fase, a "avaliação", ocorrem o acompanhamento, a revisão e a manutenção do projeto on-line. Busca-se identificar problemas e erros na concepção do projeto e corrigi-los em versão posterior. Esse modelo de design instrucional é bastante questionado, pois essas fases são estanques e não são revisitadas ao longo do processo. Nesse sentido, Couto e Oliveira (1999, p. 9) destacam que o processo de design deve ser compreendido "como um tecido que enreda o designer, o usuário, o desejo, a forma, o modo de ser e estar no mundo de cada um de nós", diluindo, assim, a concepção de que esse é somente um processo que deve resultar em um produto. Filatro (2004, p. 56) corrobora essa visão, já que o processo de design 
Silveira, G; Ribeiro, A; Pedrosa, A; Villela, M; Ruiz, S.

não se reduz à face visível de produtos instrucionais, nem se refere apenas a um planejamento abstrato de ensino, mas reflete a articulação entre forma e função, a fim de que se cumpram os objetivos educacionais propostos.

O processo de design de um projeto educacional, como o aqui analisado, "precisa permitir prática flexíveis para dar conta de questões não previstas" (RIBEIRO, 2012, p. 61). Tais práticas são imprescindíveis para o sucesso do projeto no contexto on-line. $O$ processo de design dos projetos digitais de inglês na educação básica, apesar de seguir as mesmas fases descritas anteriormente, foge do modelo tradicional e está em consonância com o DIC, pois partindo da necessidade de acolhimento e atendimento aos estudantes do EF II e EM, em decorrência da pandemia, as unidades foram planejadas, elaboradas e postadas no ambiente digital e, à medida que eram realizadas, eram também avaliadas, o que levou a modificações no design do projeto ao longo de sua implementação. Dentre tais mudanças, podemos citar as unidades Time to Play e The Sound of Music, que foram elaboradas e inseridas posteriormente ao início do projeto.

A unidade Time to Play foi composta por jogos on-line, organizados sequencialmente em níveis de dificuldade. Alguns tipos de jogos foram: jogo da memória, caça-palavras, "Quem quer ser um milionário?", palavras cruzadas e quizzes on-line, elaborados a partir de diferentes plataformas, como o Kahoot!. É importante frisar que alguns dos jogos foram encontrados prontos na internet, porém a maioria foi desenvolvida por nossa equipe de professores com base nos assuntos trabalhados em cada projeto específico.

A unidade The Sound of Music obedeceu à mesma estrutura das demais, como descrito anteriormente: Agenda do Dia; atividades "pre", "while" e "post" para os textos orais e escritos; Language Corner e Challenge!. Tais atividades foram elaboradas a partir de áudios e videoclipes, lançando mão das características multimodais típicas da música como gênero discursivo-textual para a compreensão da canção. Essa unidade apresentou também um tópico intitulado "Links Interessantes", onde foram indicados sites com mais informações sobre o tema da música ou sobre os seus artistas, além de outras versões da canção trabalhada. Como exemplo do trabalho desenvolvido nessa unidade, podemos destacar o sing-along, na atividade Challenge!, no qual os estudantes do $6^{\circ}, 7^{\circ}$ e $8^{\circ}$ anos do EF foram desafiados a cantar as músicas e a contar, no fórum da unidade, como foi a experiência, através da postagem de um áudio ou vídeo. No 9a ano do EF e no 1ำ ano do EM, por exemplo, os alunos foram convidados a criar suas próprias playlists a partir de canções sobre o meioambiente e, no $2^{\circ}$ e $3^{\circ}$ ano do EM, os alunos tiveram a oportunidade de escrever uma mensagem de esperança para seus colegas em meio à pandemia.

O desenho original do projeto não previa tais unidades, apenas aquelas descritas anteriormente, entretanto, ao longo do projeto, nas mensagens enviadas e nas respostas às tarefas executadas, os alunos demonstraram interesse em jogos e músicas. A equipe de língua inglesa também considerou a importância pedagógica dessas unidades. GodwinJones (2014) aponta que os jogos digitais permitem o aprendizado de línguas estrangeiras por serem organizados em ambientes interativos e/ou imersivos onde a língua alvo é usada repetidamente, oportunizando o aprendizado em contexto de forma coerente. Quanto às músicas, elas já fazem parte da realidade dos estudantes e, além de possibilitarem o trabalho de habilidades linguísticas, de acordo com Santos e Pauluk (2008), permitem também explorar outras questões de ordem cultural, pois carregam em si informações ideológicas, morais, históricas etc. Dessa forma, a aprendizagem pode ser mais significativa para os alunos. As atividades com música também se caracterizaram como uso de material autêntico, pois não visaram ao trabalho de aspectos linguísticos específicos, mas sim contribuíram para que os estudantes tivessem contato com a língua usada na vida real.

Outro ponto repensado, a partir da análise do projeto em sua implementação, foi a frequência da disponibilização de novos conteúdos para os estudantes e a organização de trabalho da equipe. Primeiramente, a equipe de professores havia 
planejado disponibilizar as atividades semanalmente, mas avaliou que as unidades previstas estavam demasiadamente robustas, o que possivelmente exigia muito tempo dos alunos para executá-las, ocasionando um eventual acúmulo de tarefas ao longo da semana. O volume de trabalho para elaborar as atividades de forma adequada para a plataforma também foi considerado. O cronograma foi, então, revisto e as unidades passaram a ser disponibilizadas quinzenalmente.

Em relação à estruturação do trabalho da equipe, no início da implementação do projeto, os professores estavam organizados em duplas que, responsáveis por determinados anos de escolaridade, elaboravam as unidades, as inseriam no AVACAp e gerenciavam a mediação das produções dos alunos, esclarecendo suas dúvidas, dando feedback às suas respostas, incentivando, via e-mail, aqueles que não estavam participando, dentre outras atribuições.

No decorrer do trabalho, entretanto, as diferentes expertises dos componentes da equipe se evidenciaram e alguns professores demonstraram ter mais conhecimento pedagógico e técnico para elaborar as unidades e também para lidar com o ambiente virtual. Por outro lado, outros demonstraram ter mais familiaridade com estratégias e ações de mediação e, assim, passaram a trabalhar no contato com os estudantes. Com isso, para que o trabalho se desenvolvesse com mais fluidez ao longo da implementação do projeto, o grupo de professores passou a se dividir em duas equipes: "elaboração" e "mediação".

Todos esses movimentos mostram que 0 processo de design dos projetos digitais de inglês na educação básica, ao mesmo tempo em que se configurou como um produto pronto a ser acessado pelos estudantes, também permitiu práticas flexíveis por parte da equipe de professores envolvida no projeto, em uma concepção baseada no DIC. Tais práticas se concretizaram na inserção de unidades para atender às demandas dos estudantes e nas questões de gerenciamento de tempo, na mudança de cronograma de disponibilização das atividades e na reconfiguração da divisão do trabalho da equipe, todos repensados e ressignificados ao longo das fases do design, com vistas ao caráter recursivo que uma plataforma virtual como o AVA permite.

$O$ design de um projeto on-line não é simples. $O$ gerenciamento do trabalho no AVACAp, as escolhas didáticas em termos de ferramenta e expertise técnica e a elaboração das unidades para o trabalho com a língua inglesa representam ações bastante complexas. Assim, escolhemos o Project Based Learning (PBL) para o alinhamento a um arcabouço teórico-metodológico que pautasse o trabalho de forma significativa para os estudantes, como explicitaremos a seguir.

4 Project Based Learning: as atividades de inglês como oportunidades de reflexão e ação

Project Based Learning (PBL), ou Aprendizagem Baseada em Projetos, é uma metodologia de ensino-aprendizagem centrada no aluno, que é desafiado a responder a uma situação problema ou questionamento, autênticos e significativos, por meio de uma série de tarefas, pesquisas e reflexões, de forma colaborativa e autônoma, culminando em um produto final também autêntico e público. (BELL, 2010; BLUMENFELD, 1991; BLUMENFELD e KRAJCIK, 2006; BENDER, 2014).

As bases teóricas das ciências de aprendizagem do PBL são descritas por Krajcik e Blumenfeld (2006, p. 318) como sendo "(1) construtivismo ativo, (2) aprendizagem situada, (3) interações sociais e (4) ferramentas cognitivas." Espera-se que o estudante construa significado tomando como base as suas próprias experiências e interações com o mundo real, em um contexto autêntico, à medida que participa ativamente da realização das várias etapas de implementação do projeto e compartilha saberes com seus pares - outros estudantes, professor e comunidade - por meio de diferentes tipos de interações sociais e através do uso de tecnologias de aprendizagem, tais como coleta, análise e apresentação de dados, construção de modelos, elaboração de documentos multimodais, 
Silveira, G; Ribeiro, A; Pedrosa, A; Villela, M; Ruiz, S.

dentre outras (KRAJCIK e BLUMENFELD, 2006, p. 319-320). Então, os projetos PBL nascem de situações e de questões do mundo real, não pertinentes exclusivamente ao meio escolar/acadêmico, e seguem um encaminhamento comum, como descrevem KRAJCIK e BLUMENFELD (2006, p. 318): a) partem de uma pergunta motriz ou problema a ser resolvido; b) consideram as vozes e escolhas dos estudantes; c) promovem a investigação; d) oportunizam a colaboração e o engajamento dos participantes na busca de solução de problemas; e) fomentam a construção de andaimes com as tecnologias da aprendizagem, de modo que os estudantes possam participar de atividades cada vez mais complexas.

Nessa perspectiva, Larmer, Mergendoller e Boss (2015) definiram o que chamam de "Golden Standards PBL", padrões de ouro do PBL: problema desafiador ou questão, investigação sustentada, autenticidade, voz e escolha dos estudantes, reflexão, crítica e revisão e produto público e autêntico (LARMER, MERGENDOLLER e BOSS, 2015, p. 34). Esses elementos essenciais nos projetos PBL se relacionam de forma cíclica e recorrente em torno do aprofundamento do conhecimento das disciplinas de determinado projeto e de habilidades que os estudantes precisam usar e aplicar e serem capazes de transferir para outros contextos no futuro.

Com o desenvolvimento tecnológico e a popularização de recursos on-line, o PBL ganha uma vertente que incorpora a tecnologia digital como aspecto fundamental: o IT Assisted PBL ou PBL-IT aprendizagem baseada em projetos mediada por tecnologia. Nesse contexto, a tecnologia não é apenas usada na realização de tarefas desenvolvidas ao longo do projeto, mas se torna um objetivo de aprendizagem por parte dos alunos com vistas ao letramento digital, pois incorpora a tecnologia, para além da lógica instrumental, como uma ferramenta com potencial para gerar espaços de aprendizagem e interação, uma vez que é no ambiente tecnológico que o projeto é desenvolvido (MOURSUND, 1999, p.7).

Como Moursund (1999, pp. 72-73) também esclarece, além dos objetivos relacionados ao conteúdo do tema a ser investigado nos projetos, em um PBL-IT espera-se que os estudantes aprendam a tecnologia por eles mesmos, ajudem outros estudantes e demonstrem seus conhecimentos tecnológicos em seus "produtos, apresentações e performances", o que caracteriza a culminância do projeto. No entanto, é importante ressaltar que, no viés do PBL-IT, não é necessário que o aluno tenha conhecimento profundo sobre ferramentas tecnológicas para acompanhar as atividades mediadas pelo computador. Nesse sentido, Moursund (1999, p. 6) esclarece que

o projeto então serve como uma experiência motivacional e dá um contexto autêntico para aprender mais sobre a ferramenta. Aprender sobre a ferramenta e usar a ferramenta para levar o projeto são [atividades] completamente integradas. (tradução nossa)

Ainda, o uso de tecnologia "pode ter um papel poderoso em enriquecer a motivação dos estudantes e do professor em fazer projetos e em ajudar estudantes e professores a implementá-los" (BLUMENFELD, 1991, p. 384, tradução nossa). Isso porque a tecnologia, parte importante do cotidiano dos jovens estudantes, é autêntica, dinâmica e atraente. Além disso, a tecnologia auxilia o professor no seu planejamento, elaboração e correção de tarefas, bem como agiliza o envio de feedback e a realização de mediação.

$\mathrm{Na}$ tentativa de mitigar as consequências do distanciamento social e promover o estabelecimento de vínculos com os estudantes do instituto, concluímos que o PBL-IT seria uma metodologia viável para a elaboração dos nossos projetos. Outro ponto de destaque é que os projetos PBL são, em sua natureza, interdisciplinares. Em nosso caso específico, com projetos do componente curricular Língua Inglesa, o idioma nos possibilita transitar em diversas áreas acadêmicas com facilidade, dado o status de língua franca que o inglês alcançou na contemporaneidade. É possível desenvolver atividades a partir de textos orais, escritos e multimodais, como vídeos e músicas, sobre os mais diferentes assuntos e, ainda assim, trabalhar conteúdos linguísticos característicos dessa língua, estratégias de leitura, produção oral e escrita, bem como explorar elementos textuais e discursivos. É possível também ir além e despertar o interesse dos estudantes para aspectos culturais, objetivando um melhor entendimento da sociedade global 
na qual todos nós estamos inseridos e desenvolver o letramento crítico dos nossos jovens alunos.

Para exemplificar como os projetos digitais em inglês na educação básica se materializaram tendo o PBL-IT como base teórico-metodológica, apresentamos o cronograma do $7^{\circ}$ e $8^{\circ}$ anos, cuja temática foi "a rotina durante o isolamento social". O projeto foi intitulado "View from my window" e tinha o objetivo geral de levar os estudantes a investigar suas rotinas, refletir sobre seus hábitos durante a quarentena e também agir dentro de suas possibilidades para lidar com os desafios frente ao isolamento social. O projeto foi composto por 8 unidades, disponibilizadas quinzenalmente, conforme cronograma apresentado na Figura 1.

Figura 1- Cronograma do projeto de $7^{\circ}$ e $8^{\circ}$ anos EF.

\begin{tabular}{|c|c|c|c|c|c|c|c|}
\hline $\begin{array}{c}\text { Quinzena } \\
1\end{array}$ & $\begin{array}{c}\text { Quinzena } \\
2\end{array}$ & $\begin{array}{c}\text { Quinzena } \\
3\end{array}$ & $\begin{array}{c}\text { Quinzena } \\
4\end{array}$ & $\begin{array}{c}\text { Quinzena } \\
5\end{array}$ & $\begin{array}{c}\text { Quinzena } \\
6\end{array}$ & $\begin{array}{c}\text { Quinzena } \\
7\end{array}$ & $\begin{array}{c}\text { Quinzena } \\
8\end{array}$ \\
\hline Ambientação & $\begin{array}{c}\text { My } \\
\text { neighborhood }\end{array}$ & $\begin{array}{c}\text { My place } \\
\text { and my } \\
\text { favorite } \\
\text { room }\end{array}$ & $\begin{array}{c}\text { Time to } \\
\text { play! }\end{array}$ & $\begin{array}{c}\text { My routine } \\
\text { during } \\
\text { quarantine }\end{array}$ & $\begin{array}{c}\text { My eating } \\
\text { habits }\end{array}$ & $\begin{array}{c}\text { The sound } \\
\text { of music }\end{array}$ & $\begin{array}{c}\text { Tareáa de } \\
\text { culminância } \\
\text { e auto } \\
\text {-avaliação }\end{array}$ \\
\hline
\end{tabular}

Para uma melhor compreensão do projeto, tomaremos como exemplo a quinzena 6, intitulada "My eating habits", em que as atividades foram articuladas em torno da pergunta motriz "Como estão os meus hábitos alimentares na quarentena?". Essa pergunta pretendia levar ao questionamento de uma situaçãoproblema real: a alimentação e a mudança de hábitos alimentares, comuns em períodos particularmente atípicos, como o desta pandemia. Como nos outros projetos, as unidades começaram com uma "Agenda do Dia" seguida do Vocabulary log, como ilustrado na Figura 2.

Figura 2 - Agenda do dia e Vocabulary Log

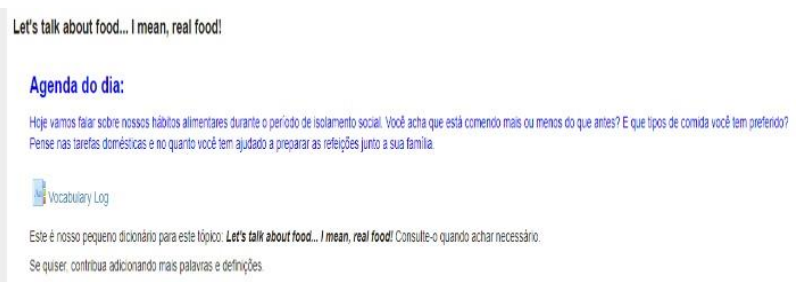

Em seguida, as atividades de Pre-Reading prepararam para a leitura do texto "Experts warn about eating habits during quarantine". Nessas atividades, os estudantes foram convidados a participar de um fórum de discussão para trocar informações e refletir sobre como estavam contribuindo para o preparo da alimentação em casa, com suas famílias. Nesse fórum, também compararam as suas dietas antes e durante a quarentena. Após participarem do fórum, os estudantes tiveram acesso a um jogo de associação de palavras e imagens, cujo objetivo foi trabalhar itens lexicais relativos ao tema da unidade. Através desse jogo, os alunos revisitaram vocabulário relacionado a comida, já estudado em anos anteriores, e tiveram a oportunidade de ativar conhecimento prévio sobre essa temática, o que objetivava facilitar a compreensão geral e específica do texto, como mostra a Figura 3.

Figura 3 - Jogo de associação sobre comida (Pre-Reading)

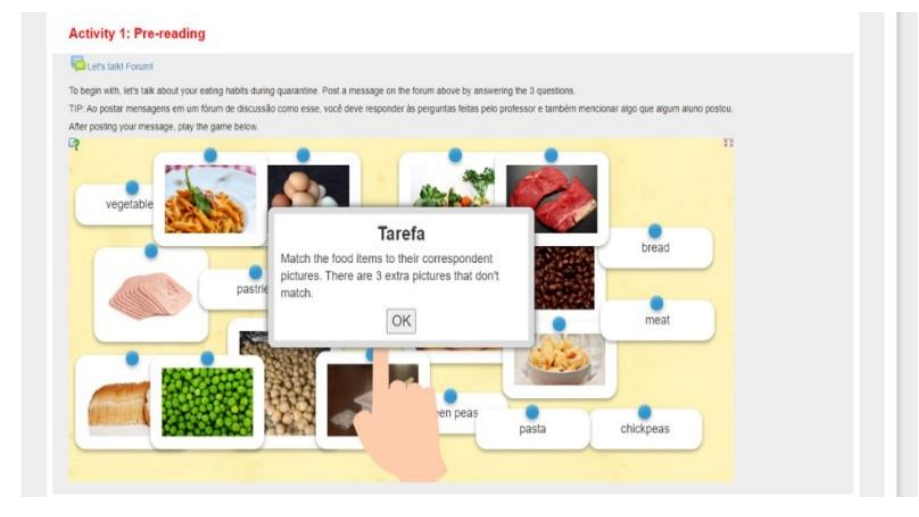

$\mathrm{Na}$ atividade While-reading, os alunos realizaram tarefas de compreensão das informações gerais e específicas do texto (Figura 4). Instruções em português sobre como lidar com a leitura foram disponibilizadas para contribuir para o desenvolvimento da autonomia de ampliar o conhecimento disciplinar dos estudantes e de fomentar o desenvolvimento de suas habilidades, pressuposto importante na perspectiva do PBL.

Figura 4 - Atividades de while-reading 
Activity 2: While-reading

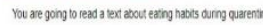

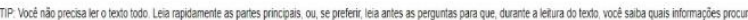

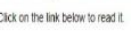

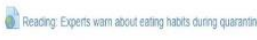

$\checkmark$ Maswer the questions ant Tor true of For tabe

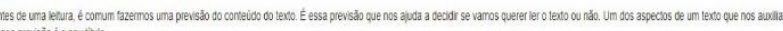

ssa pereisio éo seu

$\checkmark$ Predcing concent trom ne rete

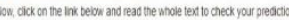

ail Herst

Seguindo o desenho didático planejado, as atividades intituladas Language Corner tiveram o objetivo de apresentar conteúdo linguístico e cultural, sem propostas de prática. Nesse projeto, o elemento abordado, a partir da temática dos textos trabalhados, foi o significado da expressão comfort food ou comfort snack, como podemos observar na Figura 5.

Figura 5 - Language corner

Comfort snack / Comfort food
In the 2 nd text, "chocolate" is referred to the expression "comfort snack".
Let's check what it means: a food that you like very much and you often eat
when you are sad.
This expression can also be "comfort food". It comes from the use of the
adjective "comfortable", which opposite is "uncomfortable". Near opposites can
be: "harsh", "Unpleasant", and "hard".
Other synonyms for "comfortable" are: "comfy", "cozy" and "easy".

A atividade Post-reading apresentou dois vídeos curtos: um sobre uma receita de feijoada e outro sobre mac and cheese, dois pratos de diferentes origens. Após assistirem aos vídeos, os estudantes responderam a um questionário sobre as suas preferências em relação aos dois pratos culinários, dizendo qual gostariam de preparar, qual julgavam ser mais fácil de elaborar etc.

Posteriormente, na atividade Challenge!, os estudantes foram desafiados a postar uma foto de um prato que apreciavam e, em seguida, compartilhar a receita com os demais participantes do projeto. Um exemplo do gênero "receita culinária" foi apresentado como um ponto de referência para a realização da tarefa, como ilustrado na Figura 6.

Figura 6 - Challenge!

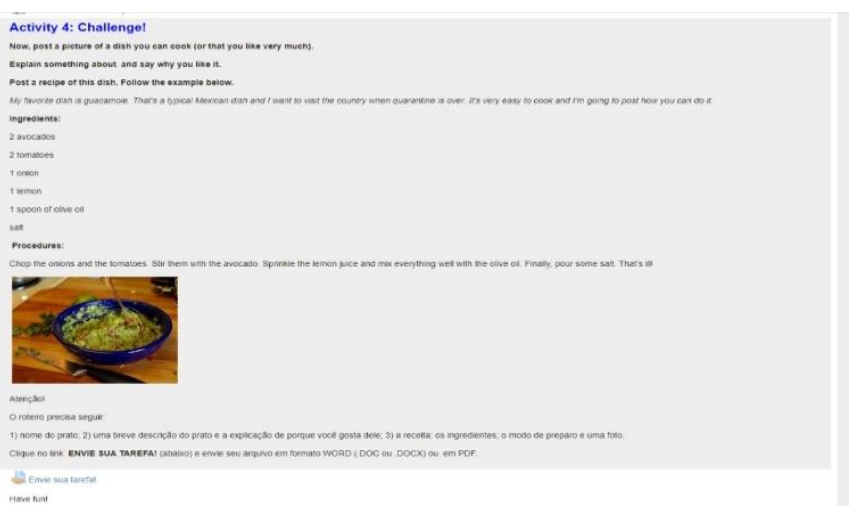

Em seguida, os alunos foram desafiados a compartilhar suas receitas em um site especializado, acessado por pessoas do mundo todo, o que configura um produto público e autêntico e, além disso, representa uma oportunidade de desenvolvimento de letramento digital ${ }^{1}$, coadunando com o PBL e o PBLIT. Por fim, os estudantes foram convidados a avaliar o que aprenderam com os trabalhos desenvolvidos na quinzena, na atividade Before you leave, como mostra a Figura 7.

Figura 7 - Atividade Before you leave

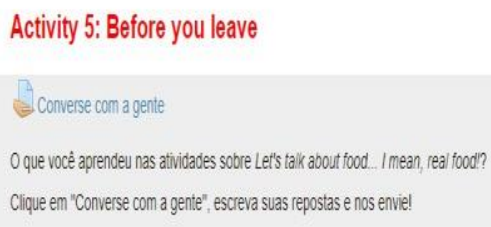

As demais unidades apresentaram configuração semelhante e contribuem para a construção da culminância do projeto. No caso do Projeto The view from my window, a partir das unidades quinzenais - que se iniciaram com propostas de observações do entorno da vizinhança em tempos de pandemia e caminharam para reflexões sobre os hábitos e rotinas na quarentena - os estudantes foram convidados a fotografar a vista de suas janelas e a postar a imagem em um site, como participação na montagem colaborativa de um mural on-line.

Figura 8 - Tarefa de culminância 


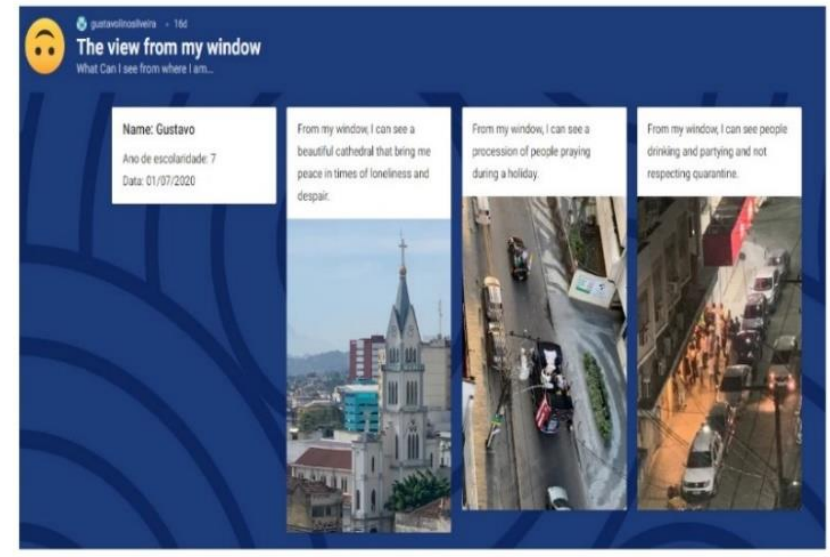

Para colaborar com a construção desse mural, um tutorial explicando o uso da ferramenta Padlet foi disponibilizado, o que representou mais uma oportunidade de letramento digital e oportunizou a utilização do meio digital como veículo da produção e demonstração do conhecimento adquirido ao longo da investigação sustentada e da reflexão proposta pela metodologia com base em projetos.

\section{Considerações finais}

A pandemia nos impôs mudanças na forma como lidamos com as diferentes esferas da atividade humana. A necessidade de repensar e ampliar nossas habilidades tecnológicas e modos de compreensão do que seja ensinar e aprender tornou-se, nesse cenário, ainda mais evidente. Os projetos digitais de inglês na educação básica do CAp-UERJ se configuraram em processo e produto, a partir de atividades elaboradas com base no PBL, o que nos proporcionou a oportunidade de rever de maneira crítica a nossa forma de trabalho e a visão dos papéis de professores e alunos, conforme a concepção de design instrucional contextualizado.

Foram apresentadas unidades organizadas em atividades, com objetivos que transcenderam a aprendizagem de conteúdos específicos da língua inglesa, tais como regras gramaticais, por exemplo. Foram traçados itinerários digitais capazes de promover a autonomia, o protagonismo e a ampliação do repertório de conhecimentos dos estudantes, além do desenvolvimento do domínio tecnológico. As atividades elaboradas sob 0 viés do PBL-IT viabilizaram reflexões e ações que levaram à criação de produtos públicos e autênticos por meio de ferramentas digitais.

Trabalhar on-line traz novos desafios, como a possibilidade de revisão e de reestruturação constantes durante a implementação das atividades, a partir de percepções, como por exemplo, aquelas que surgem da contribuição dos participantes. Outro desafio é a reorganização da divisão de trabalho pela equipe responsável pelo projeto, valorizando expertises e oportunizando a ampliação de repertórios na busca de realizar o "inédito viável" (LIBERALI, 2020). Nesse sentido, os projetos digitais de inglês não pretendem se apresentar como uma solução para questões pedagógicas, mas como um caminho possível para o ensino de línguas em tempos de pandemia.

\section{REFERÊNCIAS}

BELL, Stephanie. Project-Based Learning for the 21st Century: Skills for the Future. The Clearing House, Danbury, v. 83, n. 2, p.39-43, jul. 2010.

BENDER, William. Aprendizagem Baseada em Projetos: Educação Diferenciada para o Século XXI. Tradução de Fernanda de Siqueira Rodrigues. 1.ed. Porto Alegre: Penso, 2014. 156 p.

BLUMENFELD, Phyllis. et al. Motivating Project Based Learning: Sustaining the Doing, Supporting the Learning. Educational Psychologist, The University of Michigan, v. 26, n. 3 e 4, p. 369-398, jun. 1991.

BUZATO, Marcelo El. Khouri. Desafios empíricosmetodológicos para a pesquisa em letramentos digitais. Trabalhos em Lingüística Aplicada, Campinas, n. 1, p. 45-62, jan./jun. 2007. Disponível em: <https://www.scielo.br/pdf/tla/v46n1/a05v46n1.pdf>. Acesso em: 09 de dez. de 2020.

COUTO, Rita Maria de Souza; OLIVEIRA, Alfredo J de. (Orgs.). Formas do design: por uma metodologia interdisciplinar. Rio de Janeiro: PUC-Rio, 1999. 191 p.

FILATRO, Andrea. Design instrucional contextualizado: educação e tecnologia. $1^{\underline{a}}$ ed. São Paulo: Editora SENAC, 2004. 215 p.

; PICONEZ, Stela. Design instrucional contextualizado. In: CONGRESSO INTERNACIONAL DE EDUCAÇÃO A DISTÂNCIA ABED. Salvador,2004.Disponível em <http://www.abed.org.br/congresso2004/por/htm/049TC-B2.htm>. Acesso em: 09 jul. 2020. 
FREIRE, Paulo. Pedagogia da autonomia: Saberes necessários à prática educativa. 3. ed. São Paulo: Paz e Terra, 1997.

GODWIN-JONES, Robert. Games in language learning: Opportunities and challenges. Language Learning \& Technology. Hawaii, v. 18, n. 2, p. 9-19, jun. 2014.

KRAJCIK, Joseph. e BLUMENFELD, Phyllis. ProjectBased Learning. In: The Cambridge handbook of the Learning Sciences. R. Keith Sawyer (ed.). Cambridge: Cambridge University Press, 2006, 609 p. p. 317-333.

KRASHEN, Stephen. Second language acquisition and second language learning. ed California: University of Southern California, Pergamon Press, 2002. 151 p.

LARMER, John; MERGENDOLLER, John; BOSS, Suzie. Setting the Standard for Project Based Learning: A Proven Approach to Rigorous Classroom Instruction. Alexandria: ASCD, 2015, 238 p.

LIBERALI, Fernanda Coelho. Construir o inédito viável em meio à crise do coronavírus. In: LIBERALI, Fernanda Coelho et al (Org.) Educação em tempos de pandemia: brincando com um mundo possível. Campinas: Pontes Editoras, 2020. 402 p. p.13-21.

MOURSUND, David. Project-Based Learning Using Information Technology. 1. ed. Oregon: International Society for Technology in Education, 1999, 141 p.

REIGELUTH, Charles. What is instruction-design theory and how is it changing. In: Instructionaldesign theories and models: a new paradigm of instruction theory. New York: Routledge, 1999. 728 p.

RIBEIRO, Andrea. Design e redesign de curso on-line na perspectiva da Teoria da Atividade. Polifonia. Rio de Janeiro, v. 19, n. 25, p. 61, mai. 2012.

SANTOS, Jacinta; PAULUK, Ivete. Proposições para o ensino de língua estrangeira por meio de músicas. Paraná, 2008. Disponível em: <http://www.diaadiaeducacao.pr.gov.br/portals/pde/ar quivos/752-4.pdf>. Acesso em: 10 jul. 2020.
SILVEIRA, Gustavo Estef Lino da et al. Projetos Digitais de Inglês na Educação Básica: reflexões, possibilidades e ações em tempos de pandemia. Signo, Santa Cruz do Sul, v. 46, n. 85, p. 134-144, jan. 2021. ISSN 1982-2014. Disponível em: $<$ https://online.unisc.br/seer/index.php/signo/article/view /15684>. doi:https://doi.org/10.17058/signo.v46i85.15684. 